\title{
UK rejects compulsory mental health treatment
}

Attempts to overhaul mental health law in England and Wales suffered a withering blow last month when a Joint Parliamentary Committee described the draft bill as "fundamentally flawed" and sent it back to committee.

The British Medical Association condemned the bill, which $\infty$ proposed new powers for com$\approx$ pulsory treatment and assessment of outpatients in the community setting. These include powers to compel patients to make themselves available for assessment and to reside at specified locations. The BMA advised the committee to "tear the proposals up and start again."

The plans are aimed at better protecting the public from people with dangerous and severe personality disorders. Over the past few years several murders carried out by people with severe mental illness have provoked furious calls for firmer control of dangerous patients.

The Joint Parliamentary Committee that was set up to scrutinize the bill stated that the plans would "force too many people into compulsory treatment" and that it "places too great an emphasis on protecting the public from a small minority of dangerous mentally ill people."

It said it feared that the proposed powers could be used to enforce treatment on people who are a "nuisance" but who don't pose any risk to the public.

In a statement to $C M A 7$, the UK Department of Health wrote that it would review the committee's report carefully. "However ... any legislation must ensure that there is a proper balance between protecting the rights and lives of our citizens alongside the rights of the individual." - Colin Meek, Wester Ross, Scotland

\section{Drug Safety}

\section{National consumer drug safety network launched}

Citing the recent withdrawal of refecoxib (Vioxx), members of a new national consumer network say Health Canada and Canadian doctors are failing in their duty to protect the public from harmful drugs.

"The evidence is clear, something is broken in the system and we should get busy and fix things," BC family physician Dr. Warren Bell said at the Mar. 18 Vancouver conference that gave birth to the network PharmaWatch/PharmaVeille.

Bell is a board member of the previous PharmaWatch, a Vancouver-based advocacy group spearheading the new organization which aims to involve the public in every stage of Canada's

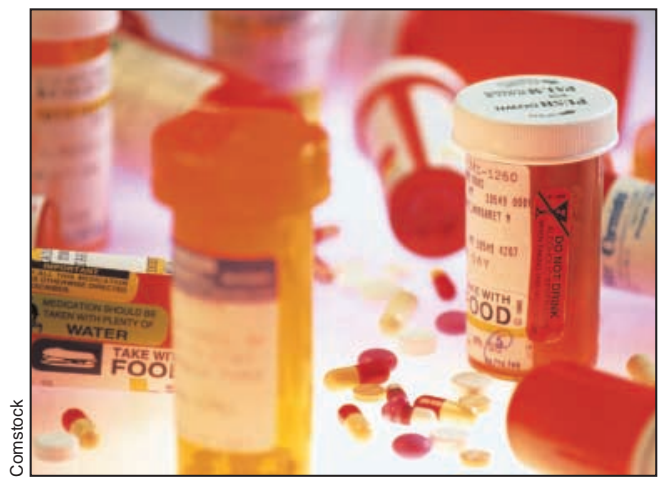

drug regulation process.

The other two founding groups are DES Action Canada, which was formed in 1982 in response to serious adverse reactions to DES (diethylstilbestrol), and l'Union des consommateurs, a Montréal-based consumer group that has launched a class action suit against Pfizer, the maker of celecoxib (Celebrex).

Although the conference focused on how to improve direct consumer reporting of adverse drug reactions, participants said consumers must also be part of other stages, including drug approvals and postmarket surveillance.

"We think citizens have a right to be involved in the approval process," said PharmaWatch and network head Colleen Fuller.

"The public should have full access to information about clinical trials being conducted, the reasons why a drug has been approved or not approved. And that means the government has to open the doors to people, and citizens have to step forward themselves."

Dr. James Wright, managing director of the Therapeutics Initiative at the University of British Columbia, illustrated the inadequacy of the current system through the example of COX-2 inhibitors.

In early 2001 Wright published information from a rofecoxib trial showing that the drug was associated with an increase in life-threatening events (CMAf 2002;167:1131-7).

"The regulators are passive," says Wright.

The network hopes to create a bilingual Web-based source of drug information; help Canadians play an active role in developing public policies that reduce the harmful effects associated with prescription drugs, including working for a ban on directto-consumer advertising; support equitable access to safe medicines and non-drug therapies; and encourage consumer reporting of adverse drug events.

Health Minister Ujjal Dosanjh recently announced Health Canada's new commitment to greater transparency and increased consumer involvement in decision-making about drug safety (CMA7 2005;172:733). Alicia Priest, Victoria 